\title{
Study on the influence of the slope-angle to the bullet projectile
}

\author{
YANG Li-zhi, CHENG Yong-cai \\ Ordnance Engineering College, Shijiazhuang 050003, China
}

Keywords: bullet projectile, slope-angle, engraving resistance

\begin{abstract}
The engraving process of projectile is a very complicated mechanics process, In this paper, the artillery projectile engraving tube process is the research object, using the WDW-T200 microcomputer control electronic universal tension and compression testing machine of projectile and barrel samples of projectile with static indentation test $。$ The purpose is to explore the antiaircraft artillery projectiles in the engraving process, engraving resistance under the condition of different slope bore size variation and analysis to draw general conclusions, in order to facilitate for barrel bore slope design and model design of projectile provide theoretical reference. At the same time, the relationship between the taper of the bore and the length of the initial part is very important for studying the reliability of the gun and improving the firing accuracy and safety.
\end{abstract}

\section{Introduction}

The squeeze process of projectile is a very complicated mechanical process. With projectile base pressure increases, the projectile movement, playing with embedded rifling and plastic deformation, and gradually to squeeze into the barrel bore ${ }^{[1]}$. With the projectile diameter than the bore diameter line is slightly larger, so the projectile began after exercise, when resistance increases ,the belt is gradually into the rifling. When the band completely into the rifling, the resistance reaches the maximum, the belt is extruded out of the trench and is consistent with the rifling, this process is the engraving process of projectile.

During the period of bullet engraving is an important factor in the impact of the initial trajectory conditions, has important practical significance to research and develop the new type of projectile in bore wear and improving the current firing accuracy of projectile ${ }^{[2-3]}$. The pill tucking in a very short period of time, is difficult to measure accurately, so classical interior ballistics usually assume engraving pressure instantaneous projectile, began to exercise when it reaches, ignoring the projectile engraving process of this important. With the rising levels of scientific theory and method of continuous innovation, the conventional method of classical mechanics has been unable to meet the accuracy requirements of artillery, the conventional calculation method is only as a qualitative analysis of the reference and basis.

In recent years, domestic and foreign experts and scholars have conducted many studies on the projectile into the process ${ }^{[4 \sim 6]}$. However, they are not covered slope bore the initial part of the taper and the length of projectile engraving process shot with the engraving pressure variation in size, packed into the influence of duration, which the projectile subsequently in the pipe body attitude motion, movement time, acceleration and the final projectile muzzle speed will be have a huge impact, thus affecting the cannon firing accuracy.

This paper intends to adopt universal tension and compression testing machine of projectile and barrel under static, slow conditions squeeze test, to explore different slope chamber angle of projectile in engraving process by resistance variation for between the bore and the projectile abrasion relation, research and development new bullets do certain theoretical basis. In this paper, using the microcomputer WDW-T200 control electronic universal tension and compression testing machine make the projectile in different slope bore taper of a simulated pipe in real samples of ammunition belt static squeeze test to simulate the projectile in the rifling at the beginning of the engraving process, focusing on the barrel and the projectile engraving process by resistance of simulation, get the pill at the start to fully embedded rifling process by the resistance, through the analysis of the displacement, resistance and other related data obtained projectile with the engraving 
the relationship between resistance and taper bore slope, slope chamber length.

\section{Simulation projectile test based on WDW-T200 electronic universal testing machine}

\section{WDW-T200 microcomputer control electronic universal testing machine}

WDW-T200 microcomputer control electronic universal testing machine is mainly used for tensile, compression, bending and mechanical properties test of materials. The precision of automatic control and data acquisition system, digital adjustment can achieve data acquisition and control process. WDW-T200 electronic universal testing machine maximum test force :200KN, testing force resolution: $1 / 200000$, test force measurement accuracy: better than the $1 \%$ value. The beam displacement: $0 \sim 600 \mathrm{~mm}$, mobile speed: $0.01 \mathrm{~mm} / \mathrm{min} \sim 500 \mathrm{~mm} / \mathrm{min}$, mobile speed control precision is less than $1 \%$; the deformation of the highest resolution of $0.001 \mathrm{~mm}$, the measurement accuracy is better than $0.5 \%$ indication. In this paper test using testing machine pressing function operation, testing machine can not only provide high pressure engraving process research, but also can realize full digital control and high precision data acquisition, analysis and provided reliable conditions for the test and follow-up test data.
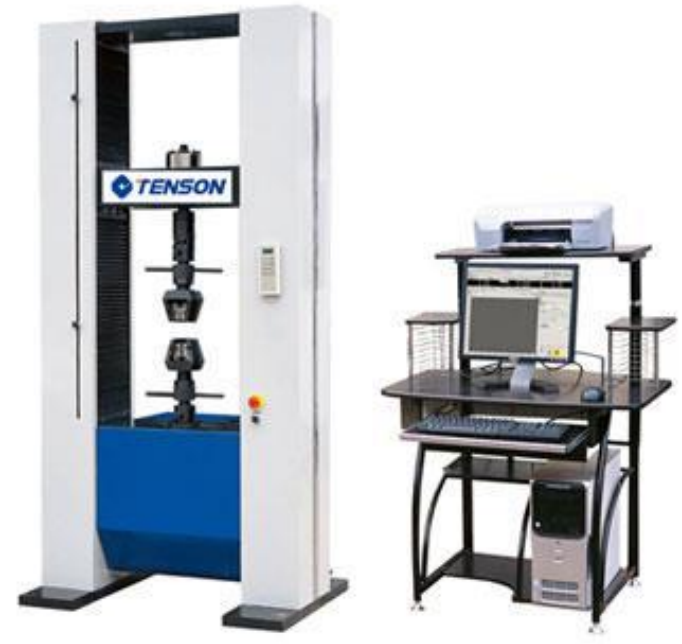

\section{Test principle of Simulation projectile}

This paper based on the simulation of WDW-T200 electronic universal testing machine projectile test of a certain type of antiaircraft artillery simulation slope does the projectile test with static force. the experimental only research the gun tube slope chamber and rifling starting department, involving very short rifle. Therefore, this paper on rifle was appropriate simplified: The rifling angle of twist is negligible, the use of 4 bar and tube parallel to the central line of the rifle to replace simulation. For the convenience of factory processing and experimental operation, simulation of barrel bore only contains a barrel part.

The projectile of bullet is a complicated mechanical process: the front section of belt and the initial slope bore contact, in a static state, projectile base pressure with gunpowder gas generation increases, increases to a certain value and propels the projectile movement began, ammunition belt slope chamber length increases with the increasing the plastic deformation with elastic, resistance increased rapidly. When the projectile with deformation reaches the maximum value does not change, the resistance remains unchanged, and the resistance decreased gradually. In the process of the elastic band squeeze into the slope bore, the taper bore and the total length of the slope will determine the plastic deformation of the elastic belt from the start to the full entry into the slope. So this paper test the electronic universal testing machine capable of specimens of axial compression function in antiaircraft projectile loading static axial load the projectiles in testing machine pressure head extrusion pressure gradually through simulated tube in the slope bore department, the indentation process is projectiles with squeeze process simulation. We set up two groups of different slope chamber angle pipe are compared in the experiment, each group was 5 times standard projectile jam to achieve several tests to reduce the error, better assurance the reliability of test data. 


\section{Test results and analysis of simulation projectile}

In this experiment, we used the $5 \mathrm{~mm} / \mathrm{min}$ 's lower pressure to carry out 2 sets of experiments on 2 simulated body tube samples, each of which had 5 bullets. All the data are WDW-T200 microcomputer control electronic universal testing machine in the process of the automatic recording. But due to the test needs test personnel manual operation in placeing specimen , adjusting the force-position of sample, and other steps, which led to the differences in operation, lead to the data obtained in the experiment may be there is gross error, so we must first of income data for gross error distinguishing and eliminating. Using Pauta criterion (3 Sigma criteria) and Romanowski criterion ( $\mathrm{T}$ test criterion) respectively for all data determinative calculation and gross errors and remove bad data from all data. After sorting out the relevant calculation and listing the main data as shown in table 1 :

\begin{tabular}{|c|c|c|c|c|c|c|c|c|}
\hline $\begin{array}{c}\text { Numbe } \\
\text { rs }\end{array}$ & $\begin{array}{c}\text { Simulat } \\
\text { ed slope } \\
\text { angle }\end{array}$ & $\begin{array}{c}\text { Sampl } \\
\text { e } \\
\text { numb } \\
\text { er }\end{array}$ & $\begin{array}{l}\text { Maximu } \\
\mathrm{m} \\
\text { pressure } \\
(\mathrm{KN})\end{array}$ & $\begin{array}{c}\text { Mean } \\
\text { value of } \\
\text { maximu } \\
\text { m } \\
\text { pressure } \\
\text { (KN) }\end{array}$ & $\begin{array}{l}\text { Maximum } \\
\text { pressure } \\
\text { correspondi } \\
\text { ng } \\
\text { deformation } \\
\quad(\mathrm{mm})\end{array}$ & $\begin{array}{l}\text { Maximum } \\
\text { deformati } \\
\text { on }(\mathrm{mm})\end{array}$ & $\begin{array}{l}\text { Maximu } \\
\mathrm{m} \\
\text { pressure } \\
(\mathrm{MPa})\end{array}$ & $\begin{array}{c}\text { Mean } \\
\text { value of } \\
\text { maximu } \\
\text { m } \\
\text { pressure } \\
(\mathrm{MPa})\end{array}$ \\
\hline \multirow{5}{*}{$1 \#$} & \multirow{5}{*}{0.1053} & $1-1$ & 61.9 & \multirow{5}{*}{67.372} & 10.4 & 92.709 & 54.58 & \multirow{5}{*}{59.4} \\
\hline & & $1-2$ & 67.3 & & 10.604 & 92.709 & 59.34 & \\
\hline & & $1-3$ & 69.95 & & 13.325 & 90.93 & 61.67 & \\
\hline & & $1-4$ & 74.2 & & 13.873 & 92.79 & 65.42 & \\
\hline & & $1-5$ & 63.5 & & 13.193 & 90.575 & 55.99 & \\
\hline \multirow{4}{*}{$2 \#$} & \multirow{4}{*}{0.0435} & $2-2$ & 52.8 & \multirow{4}{*}{53.69} & 16.149 & 97.922 & 46.56 & \multirow{4}{*}{47.34} \\
\hline & & $2-3$ & 52.15 & & 17.305 & 97.724 & 45.98 & \\
\hline & & $2-4$ & 52.65 & & 18.551 & 98.559 & 46.42 & \\
\hline & & $2-5$ & 48.45 & & 19.824 & 97.446 & 42.72 & \\
\hline
\end{tabular}

Table 1 Test Result Data

Maximum pressure calculation: $\quad P_{\max }=\frac{4 F_{\max }}{\pi d^{2}}$

In the formula, $F_{\max }$ is the maximum pressure, and $d$ is the diameter of the projectile.

According to the data of the resistance and the displacement of the pressure head obtained by the projectile test, we respectively drawn: Table 2 The curve of the 5 groups of samples of the $1 \#$ tube, Table 3 The curve of the 4 groups of samples of the $2 \#$ tube, Table 4 The average test curve of the two body tube. 


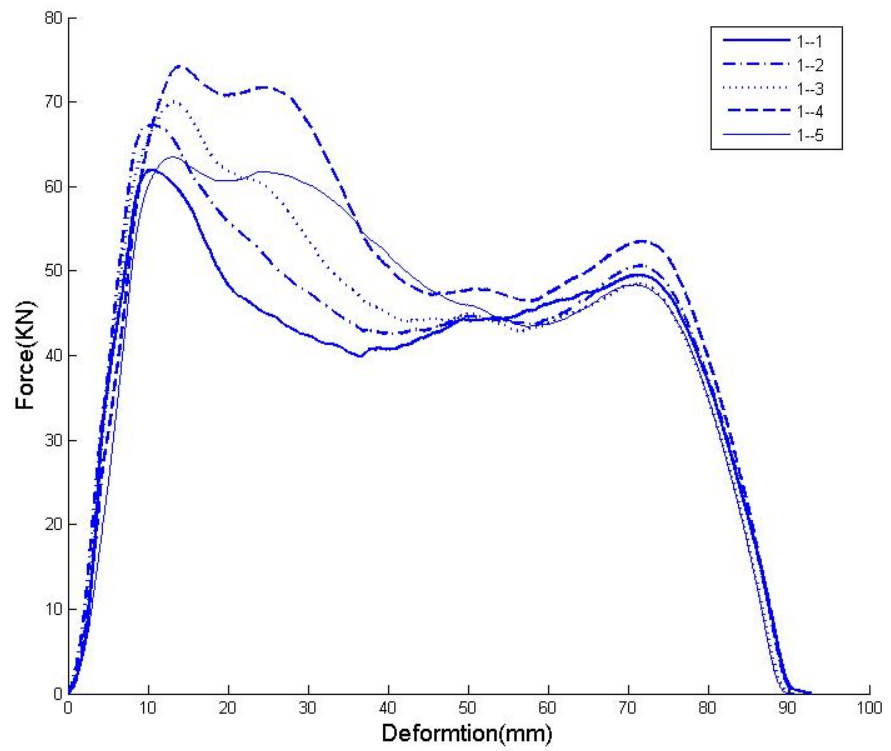

Table 2 The curve of the 5 groups of samples of the $1 \#$ tube

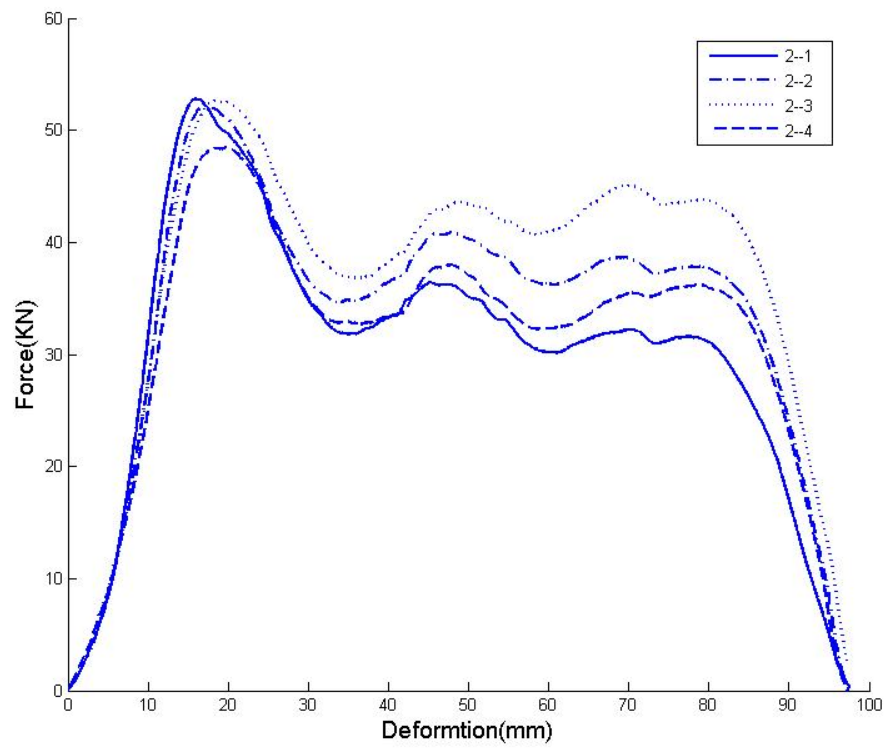

Table 3 The curve of the 4 groups of samples of the $2 \#$ tube 


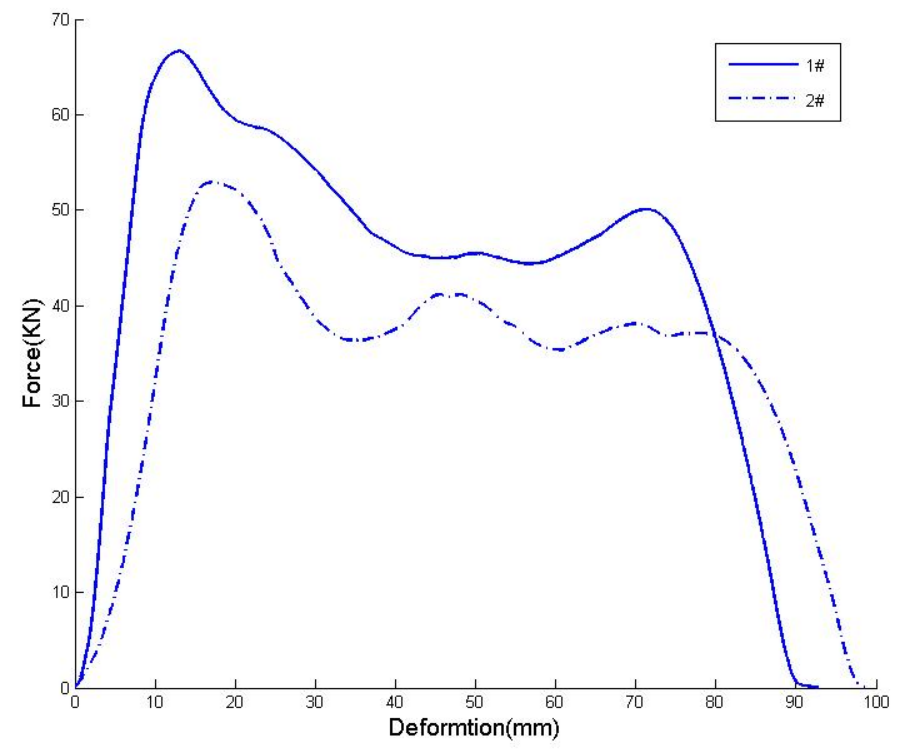

Table 4 The average test curve of the two body tube

\section{Conclusion}

5 different groups of test pressure displacement curve, can be clearly seen from the diagram in Table 2 (1\# sample), curve trend in the special position, the size of the floating point were in the acceptable error range.

In table 3 (2\# sample)for the 4 different groups of the test pressure displacement curve, 4 pressure displacement curve in the change trend, the special inflection point position and so on are showing a consistent trend.

It is obviously clear that two groups of body tube were squeezed into the displacement reaches 10-14mm 15-20mm when projectile engraving resistance reached a peak from table 2 and table 3. And two barrel bores axial length are $9.5 \mathrm{~mm}$ and $23 \mathrm{~mm}$, it can be obviously found that bore slope length and squeeze into the resistance between relationships: in a certain range, the greater the bore slope length, engraving resistance is small.

Analysis different slope bore length of the projectile process. During the process of the squeeze, the propellant combustion generates energy to propel the projectile forward movement, and the propellant is high speed combustion under high temperature and high pressure in the limited space after the bomb. Because the time of process is very short, we do not consider the different slope of the gun powder gas temperature, pressure change speed on the impact of gunpowder burning. In the process of belt completely into the rifle from just bore to contact belt, elastic belt plastic deformation is a fixed amount. In the long bore, the bore angle is relatively smooth, the projectile deformation resistance so slow changes slowly, the final resistance is small. In a relatively short bore, bore angle is relatively large, the projectile took place in a short period of time, the plastic deformation resistance changes rapidly, the final resistance is large. From the point of view of Energy Explained: Projectile with squeezed into the process by which energy is certain, for long sloping chamber, bomb with a longer axial displacement, time is longer, so the resistance is relatively small; for short slope chamber, shells with axial displacement is short, time is short, so the corresponding resistance is relatively large.

In addition to different slope muzzle length tube after the completion of the squeeze test wall hanging copper in carries on the contrast analysis, after of the same number of standard of bullet engraving test, $1 \#$ body tube inner wall length and thickness of copper layer obviously more serious than the 2nd body tube. Two body tube wall in the material, roughness and other conditions are consistent, so it can reflect that $1 \#$ body tube in the process of squeeze into the bore wall resistance larger than 2\# body tube. 


\section{Existing problems and future prospects}

Existing problems: Fewer of the rifle for the projectile in bore guiding movement of underconstrained, projectile in engraving of free unstable, experimental data fluctuations larger, so that the test and the actual situation of numerical differences.

Because the projectile in the powder gas by slope chamber is completed within the high speed period of time, so the use of universal tension and compression test rig for static squeeze cannot fully simulate the projectile in slope bore Department of state, thus obtained experimental data although it has general objective law but with actual gun firing process is different.

Due to the sample test as the standard test of projectile projectiles, the stock is less, the times of the test is limited. It has certain effect to the analysis of experimental error elimination, the comparative test conclusion.

Future work direction: Finite element simulation of engraving process using finite element software, at the theoretical level in analysis. And design and manufacture of different bore liner bore angle into real gun shooting and determination of related parameters, in order to get the effect of real shooting under different slope angle on the resistance into the bore.

\section{REFERENCES}

[1]HE Yong. The one-dimensional model and calculation of projectile's engraving resistance[J].Journal of Ballistics,1994:24-28.

[2] ZHANG Xi-fa, LU Xing-hua. Erosion interior ballistics of gun[M].Beijing: National Defense Industry Press,2001.

[3] JIN Zhi-ming. Interior ballistics of gun[M].Beijing: Beijing Institute of Technology Press,2004.

[4] SUN He-yang, MA Ji-sheng, et al. Influence of different bore structres on engraving process on projectile[J].Journal of Vibration and Shock,2011,30(3):30-33.

[5] FAN Li-xia, HE Xiang-yue. Finite element simulation and process analysis of projectile entering into barrel[J]. Acta Armamentarii,2011,32(8):963-969.

[6] HAN Wen-xiang. The simulation research on the deformation process of projectile pulling into bore[D].Nanjing: Nanjing University of Science and Technology,2009. 